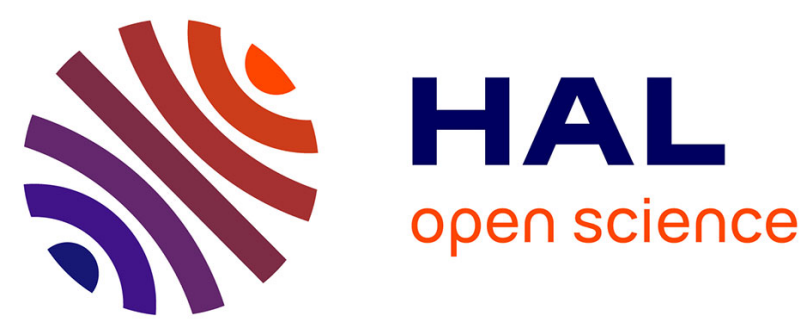

\title{
Incidence of Chronic Radiodermatitis after Fluoroscopically Guided Interventions: A Retrospective Study
}

Mélanie Guesnier-Dopagne, Louis Boyer, Bruno Pereira, Joël Guersen, Pascal Motreff, Michel D'incan

\section{To cite this version:}

Mélanie Guesnier-Dopagne, Louis Boyer, Bruno Pereira, Joël Guersen, Pascal Motreff, et al.. Incidence of Chronic Radiodermatitis after Fluoroscopically Guided Interventions: A Retrospective Study. JVIR: Journal of Vascular and Interventional Radiology, 2019, 30 (5), pp.692-698.e13. 10.1016/j.jvir.2019.01.010 . hal-02384109

\section{HAL Id: hal-02384109 \\ https://hal.science/hal-02384109}

Submitted on 22 Oct 2021

HAL is a multi-disciplinary open access archive for the deposit and dissemination of scientific research documents, whether they are published or not. The documents may come from teaching and research institutions in France or abroad, or from public or private research centers.
L'archive ouverte pluridisciplinaire HAL, est destinée au dépôt et à la diffusion de documents scientifiques de niveau recherche, publiés ou non, émanant des établissements d'enseignement et de recherche français ou étrangers, des laboratoires publics ou privés.

\section{(c) (1) $\$$}

Distributed under a Creative Commons Attribution - NonCommerciall 4.0 International 


\title{
Incidence of chronic radiodermatitis after fluoroscopically-guided interventions (FGI): a retrospective study
}

\author{
Mélanie Guesnier-Dopagne, M.D., ${ }^{* 1,2}$; Louis Boyer, M.D., PhD., ${ }^{2,3}$; Bruno Pereira ${ }^{4}$; \\ Joël Guersen ${ }^{3}$; Pascal Motreff, M.D., PhD., ${ }^{2,5}$; Michel D’Incan, M.D., PhD., ${ }^{1,2}$.
}

${ }^{1}$ Department of Dermatology, Estaing hospital, CHU Clermont-Ferrand, 1 Place Lucie Aubrac, F-63003 Clermont-Ferrand Cedex 1, France

${ }^{2}$ Clermont-Auvergne University, faculty of Medicine, 28 Place Henri Dunant, BP 38 F-63001 ClermontFerrand cedex 1, France

${ }^{3}$ Department of Radiology, Gabriel Montpied hospital, CHU Clermont-Ferrand, 58 rue Montalembert, 63003 Clermont-Ferrand cedex 1, France

${ }^{4}$ Department of biostatistics, Clermont-Auvergne University, faculty of Medicine, 28 Place Henri Dunant, BP 38 F-63001 Clermont-Ferrand cedex 1, France

${ }^{5}$ Department of Cardiology, Gabriel Montpied hospital, CHU Clermont-Ferrand, 58 rue Montalembert, 63003 Clermont-Ferrand cedex 1, France

* Corresponding author:

Mélanie Guesnier-Dopagne, Department of Dermatology, Estaing hospital, CHU Clermont-Ferrand, 1 Place Lucie Aubrac, F-63003 Clermont-Ferrand Cedex 1, France

Phone : +33 473750445 ; Fax : +33 473750446 ; E-mail : melanie.guesnier@gmail.fr

Key Words:

radiodermatitis, interventional radiology, percutaneous coronary intervention, neuroradiology

The authors declared no conflicts of interest. 


\section{ABSTRACT}

5

6 Purpose

9

\section{Results}

\section{Conclusion}

\section{a retrospective study}

To assess the incidence and risk factors for chronic radiodermatitis after FGI in high-risk patients.

\section{Materials and methods}

Between 2010 and 2016, among 55,782 patients who underwent FGI, 359 had a risk procedure for skin injury (maximal skin dose $>3 \mathrm{~Gy}$, air kerma > $5 \mathrm{~Gy}$, dose area product (DAP) $>500 \mathrm{~Gy}^{\mathrm{cm}} \mathrm{cm}^{2}$ or fluoroscopy time > 60 minutes). Ninety-one of them were examined by a dermatologist for radiodermatitis (median time after procedure 31.2 months (95\% IC [14.2-50.7]). In each case, the clinical features and topography of the skin lesions were recorded and their incidence calculated. The characteristics of the patients and of the FGI were tested as risk factors.

Eight patients $(8.8 \%)$ had chronic radiodermatitis and $19(20.9 \%)$ acute radiodermatitis. BMI, the DAP value and air kerma were the only risk factors identified.

This study shows that chronic radiodermatitis may be considered as a frequent side effect in an at-risk population. The lesions are commonly benign but extensive sclerosis can occur. Patients should be better informed about the side effects and offered a skin exam periodically. 
$\underline{\text { Introduction }}$

Skin injury secondary to ionizing radiation has been documented since the early twentieth century. Radiation promotes the local production of free radicals, which are toxic for DNA and the molecular components of cells, and the resulting cell apoptosis and necrosis induce skin inflammation. Lesions appear in the areas exposed to radiation. Clinical presentation depends mainly on the dose delivered. Within a few hours or days, doses below 6 Gy result in transient erythema, which is often unnoticed by both patients and doctors. Higher doses also induce longstanding or permanent lesions of varying appearance: hair loss, erythema, desquamation, telangiectasia, dermal sclerosis or skin atrophy and chronic ulcerations that can lead to skin carcinomas. Radiodermatitis often evolves in two successive phases, acute radiodermatitis during the first three months after irradiation, usually followed by total skin recovery or the persistence of a discrete pigmentation or skin atrophy, and many months or years later, chronic radiodermatitis that does not heal. Medical radiotherapy commonly induces radiodermatitis, but fluoroscopically guided interventions (FGI), although delivering lower doses, can also cause skin damage. Since the first reports of radiodermatitis following cardiac catheterization were published in the 1990s, $(1,2)$ more than 200 cases due to FGI have been documented (see Appendix). The cutaneous lesions are clinically similar to those induced by radiotherapy, they but have two features that help to distinguish them, a well-defined geometric shape and their location, which is determined by the FGI. In most cases, the lesions are close to the radiation emitting tube, on the back, on the scapulae or axillae areas and on the scalp. These features are helpful in differentiating FGI-induced dermatitis from other localized skin diseases, such as morphoea or mycosis.

Lesions induced by FGI can have serious cutaneous consequences even several years after the procedure and, in this event, the radiologist can be held liable. It would be beneficial, therefore, to have a better understanding of their prevalence and risk factors. However, it is likely that most cases of FGI- induced 
radiodermatitis are undiagnosed. Unlike radiotherapy, which commonly induces dermatitis and about which patients are informed, FGI is not usually accompanied by warnings about possible skin side effects. Patients are generally unaware that they have acute FGI-induced dermatitis because the radiation burn is not painful, and the initial skin lesions are too discrete to be noticed in the context of the urgency or severity of the disease that required the initial intervention. In our hospital, in accordance with national recommendations, (3) when a procedure exceeds the risk threshold for radiodermatitis, an email is sent to the radiologist indicating that a skin injury could appear in the coming weeks and that a clinical assessment of the exposed skin areas should be made for several weeks. This procedure allows detection of acute radiodermatitis but not of the chronic form. As chronic radiodermatitis progresses slowly for many months or years after FGI, only one third of patients spontaneously notice their lesions, usually when ulceration has appeared, and, at this late stage, they are unable to connect the lesions with the procedure (see Appendix).

Some studies have estimated the prevalence of FGI radiodermatitis, but the results are limited either because the authors focused on one particular form of dermatitis (i.e. skin ulcerations) or one kind of FGI (mainly coronary explorations and angioplasties) or because the data were collected retrospectively without the expertise of a dermatologist to clearly identify the lesions. According to these studies, FGI radiodermatitis was observed in 0 to $1.5 \%$ of patients. (4-7) Given this wide diversity in reported prevalence, a skin examination by a senior dermatologist was proposed to patients who had undergone FGI procedures of any kind in the previous months or years to assess the prevalence of chronic radiodermatitis and identify the risk factors for lesion onset.

\section{$\underline{\text { Materials and methods }}$}

Institutional Review Board approval was obtained for this retrospective study. The Radiology Unit database, which contains all the collected data of all the FGI procedures, was used to identify patients who had had an FGI between January 2010 and December 2016 and for whom irradiation procedures were considered at risk for radiodermatitis owing to the presence of at least one of the following criteria: exposure of the skin to more than $3 \mathrm{~Gy}$, air kerma greater than $5 \mathrm{~Gy}$, DAP exceeding 500 Gray.cm², and/or fluoroscopy exposition time longer than 60 minutes. (3, 8) During this period, 55,782 FGIs were 
conducted, 26,455 by cardiologists in the Cardiology Unit and 29,327 by interventional radiologists in the Radiology Unit. Three hundred and ninety procedures (359 patients) were at risk for radiodermatitis. Dosimetric information was provided by the device itself and periodically controlled by external audits. When available, the peak skin dose was calculated either with radiologic films or with the dedicated software em.doses. (9) A letter was sent to patients explaining the aim and design of the study and proposing a skin examination by a dermatologist. Patients who did not answer within three months were contacted by telephone. Those who accepted the offer to be examined gave their informed written consent. The following data were recorded: age of the patient at the time of the procedure, sex, BMI, comorbidities (diabetes, autoimmune disease, dysthyroidism), medical treatments taken at the time of irradiation and skin phototype. Procedure characteristics were also recorded: date and aim of the procedure, maximum skin dose, air kerma, DAP, fluoroscopy time, number of lifetime FGIs received and, if applicable, therapeutic irradiations. All skin examinations were performed by the same senior dermatologist with more than ten years' experience. Total skin examination was done with special emphasis on the areas that were exposed to radiation to identify chronic radiodermatitis. If a lesion was identified, pictures were taken, and the dermatology chart was revised by another senior dermatologist, one who had graduated twenty-eight years ago. For each patient, a thorough medical history was taken by the dermatologist, who tried to identify if there had been an occurrence of an acute dermatitis in the days or months after the FGI. As a primary outcome, the incidence of radiodermatitis was calculated. Risk factors for onset were comparatively assessed in populations with radiodermatitis and those without (for statistical analysis: see Appendix).

\section{$\underline{\text { Results }}$}

Among the 359 patients at risk for radiodermatitis, after exclusion of those who had died, who declined to participate or who were lost to follow-up, 91 patients (96 procedures) were included in the study. The skin examinations were performed in 2017 (Table 1). Median time from the procedure to clinical examination was 31.8 months $\left(95 \%_{\mathrm{CI}}\right.$ : $\left.[14.2 ; 50.7]\right)$. Eight patients had radiodermatitis (Table 2). The incidence was $8.8 \%\left(95 \%_{\mathrm{CI}}\right.$ : $\left.[3.9 ; 16.6]\right)$ per patient and $8.3 \%\left(95 \% \%_{\mathrm{CI}}:[3.7 ; 15.8]\right)$ per procedure. In univariate analysis, BMI was the only factor that was statistically significant for a risk of dermatitis 
$\left(33.1 \pm 4.1 \mathrm{~kg} / \mathrm{m}^{2}\right.$ in patients with radiodermatitis and $28.68 \pm 6$ in patients without, $\left.\mathrm{p}=0.03\right)$. However, this was not confirmed by multivariate analysis adjusted for DAP $(\mathrm{OR}=1.29$ [0.94; 1.77], $\mathrm{p}=0.11)$. None of the other patient characteristics were associated with a risk. The DAP value was a risk factor for a skin lesion (median DAP value 1421 Gy.cm² $[892 ; 1488]$ in patients with radiodermatitis versus 572 Gy.cm² $[450 ; 794]$ in patients without $(\mathrm{p}<0.001)$ as was air kerma (median air kerma $=4.3 \mathrm{~Gy}$ $[3.8 ; 5.3]$ versus 3.5 Gy $[2.5 ; 4.9] ; \mathrm{p}=0.03)$. Fluoroscopy duration was not a risk factor $(37[31 ; 59]$ vs. 45 [26; 68], $\mathrm{p}=0.47)$. Exposition to a photosensitizing drug at the moment of irradiation did not appear as a risk factor for chronic radiodermatitis $(\mathrm{p}=0.95)$. None of the other parameters tested (age, sex, skin phototype, diabetes, number of lifetime procedures) were significant. Of the 91 patients included, 19 reported transient erythema or alopecia in the days following the procedure; both manifestations were considered as acute radiodermatitis. The incidence of acute dermatitis was $20.9 \%\left(95 \%_{\mathrm{CI}}\right.$ : $\left.[13.1 ; 30.7]\right)$ per patient and $21.6 \%$ (95\% 1 : $[13.9 ; 31.2])$ per procedure. Only one of the eight patients with chronic radiodermatitis experienced acute radiodermatitis.

Chronic lesions were a non-infiltrated and non-scleral patch a few centimetres in diameter that was hypo- or, hyperpigmented (Figure a) or erythematous (Figure b) (in 2, 2, and 1 patients respectively), a large sclerotic plaque without telangiectasia (1 patient), an atrophic plaque with telangiectasia (1 patient, Figure e) and a sclerotic plaque with a large disabling and deep ulcer in another (Figures $\mathrm{c}$ and d). None of these patients had a history of autoimmune disease, dysthyroidism or previous skin cancers. Only three of them noticed the lesions and consulted a doctor: in two cases, the diagnosis of radiodermatitis was made, but in one case, the lesions were mistaken for a fungal infection.

\section{$\underline{\text { Discussion }}$}

The estimated prevalence of chronic radiodermatitis after FGI varies greatly from one study to another. Vlietstra et al. (4) estimated a frequency of $0.01 \%$ by extrapolating from 76 previously reported independent cases to a million coronary angiographies performed each year in the United States. The study of Wei et al. (5) reported an incidence of $0.34 \%$, but they only considered radiation-induced ulcers, a clinical form that is infrequent, and included only patients who had had a coronary exploration. In addition, none of the patients were examined by a dermatologist, and clinical data were collected from 
141 clinical charts only. In a series of 61 patients who had undergone a complex procedure, Kirkwood et al.

142 (6) reported no instance of radiodermatitis, but patient follow-up was short, less than one year. In a study

143 involving 400 patients who had had a percutaneous coronary intervention for chronic total occlusion, a

144 procedure that exposes patient skin to high radiation doses, Kato et al. (7) observed six (1.5\%) cases of radiodermatitis. In the present study, the whole skin of 91 patients who were considered at risk of radiodermatitis following an FGI performed between 14.2 and 57 months previously was examined by

147 a dermatologist to estimate the prevalence of skin reactions as the primary aim and to identify risk 148 factors.

Radiodermatitis was identified in $8.8 \%$ of the 91 patients. This unexpectedly high proportion is mainly due to the patient population studied. As it was impossible to examine all the patients who had a procedure during the recruitment period, only patients who were at risk for skin injury according to international recommendations were selected. $(3,8)$ This inclusion criteria was consistent with that used in previous publications. (6) In this series, the main risk factor for chronic radiodermatitis was related to FGI characteristics and, therefore, it is likely that the frequency of chronic radiodermatitis would be lower in the total population of patients who had had an FGI. This series is the first in which all of the patients were fully examined by an experienced dermatologist. This could be a further explanation of the high frequency observed since a skin specialist was able to detect discrete lesions or hidden lesions, such as on the scalp or in the pelvic area. Finally, the median time from the FGI to the skin examination (31.77 months (95\%CI [14.9-50.73]) was longer than in most previous studies, which enabled us to identify late-onset lesions. BMI was shown to be a risk factor $(\mathrm{p}=0.03)$ but only on univariate analysis. The risk exists because higher radiation doses are required to penetrate the body in overweight patients. (10) Diabetes and fair skin, like skin-debilitating situations, were not estimated to be risk factors. Owing to memory bias, it was not possible to correlate medication intake with the risk of developing radiodermatitis. As reported elsewhere, fluoroscopy duration was not a risk factor unlike the air kerma level $(\mathrm{p}=0.03)$ and the DAP value $(\mathrm{p}<0.001)$. The best way to assess skin exposure during FGI is to calculate the peak skin dose, but this measurement is often difficult to obtain even with modern equipment. and it is generally calculated. These data support the fact that, in particular for the overweight patients, procedure safety could be improved by using lower doses, keeping the X-ray tube as far away 
from the skin as possible, bringing the detector as close to the skin as possible, avoiding radiation field overlaps and using the scopic rather than the graphic mode for procedure control.

One salient point to emerge from this study is the difficulty in identifying radiodermatitis. Often, it appears clinically as visible erythema or as a pigmented non-palpable plaque. Even when the lesions are typical, with sclerosis and telangiectasias caused by radio dystrophia, (11) they may be confused with other sclerotic lesions, such as morphoea, by an unaware clinician. However, morphoea usually presents as multiple lesions versus a single lesion like in radiodermatitis. In addition, radiodermatitis occurs in specific areas corresponding to the zones exposed to radiation. $(12,13)$ Little is known about the outcome of radiodermatitis lesions. The probability of skin sclerosis, which is, with ulceration, the most disabling feature of radiodermatitis, is not known, and this study provides no new evidence. However, the only two patients in this series with a deep sclerosing lesion were those whose DAP levels were the highest (2530 and $2095 \mathrm{~Gy} / \mathrm{cm} 2$ ), unlike their BMI, exposure time and air kerma level. As ulcerative and sclerosing lesions seem to be rare, it can be assumed that, in most cases, erythema or pigmented radiodermatitis do not progress over time. To date, no cases of skin carcinoma following FGI have been reported (see Appendix). However, the possibility that many basal cell carcinomas removed by dermatologists unfamiliar with radiodermatitis were due to the radiation procedure cannot be excluded. Due to these difficulties in clinically identifying chronic radiodermatitis, patients should be clearly informed of the occurrence of adverse outcomes and offered a bi-annual lifetime dermatology consultation whenever the X-ray exposure threshold is exceeded.

Therapeutic management is not established. Excision of the lesion at the early stage of sclerosis, before massive sclerosis and ulceration, should be recommended. Surgical reconstruction in sclerotic conditions is difficult whereas fat transfer can help wound healing. $(14,15)$

The relationship between acute and chronic radiodermatitis is unclear. Acute radiodermatitis onset did not seem to be a risk factor as only one of the eight patients concerned with chronic radiodermatitis reported an inflammatory lesion just after the procedure, whereas its rate of incidence in the total population examined was $21 \%$. Acute dermatitis could have a protective role in the occurrence of chronic dermatitis, but the limited size of the population makes statistical analysis 
impossible. The biological mechanisms of acute and chronic radiodermatitis are different. Acute lesions result from cell destruction directly induced by radiation, whereas chronic lesions are due to the chronic production of TGF $\beta$, which stimulates fibroblasts and neovascularization. (16) As there is no evidence that acute irradiation results in a durable production of TGF $\beta$, "acute and chronic radiodermatitis" should be renamed as "early- and late-onset radiodermatitis", respectively. This study has some limitations. Only $25 \%$ of the patients at risk were examined either because they were lost to follow-up, declined to participate or had died. However, patient characteristics (sex, age) and irradiation parameters (total dose, air kerma level, DAP value, fluoroscopy time) in patients at risk who were examined and those who were not were compared. No differences were found (data not shown), which led us to assume that the $8.8 \%$ rate observed was the same in the unexamined at-risk patients. On the basis of the inclusion criteria, patients who had undergone several FGIs all under the risk threshold for skin injury were excluded from the study. This bias could have underestimated the incidence of radiodermatitis. (17) Also, it cannot be excluded that patients with a discrete and, thus, unknown chronic radiodermatitis, with no other dermatoses since their FGI did not feel concerned by the study when receiving our information and did not participate. This bias, if it existed, may have lowered the observed incidence of radiodermatitis. Owing to the retrospective nature of the study, many patient risk factors, such as tobacco abuse, inflammatory or nutritional status and sun exposure level at the time of FGI were unable to be taken into account and assessed. Only a prospective study could eliminate these limitations. In contrast, the fact that the patients were examined by a dermatologist and had their case reviewed by a second dermatologist lends strength to the findings of the study. First, a thorough history-taking made by a skin specialist avoided the cohort from being enriched by patients who had experienced dermatoses of any kind after FGI. Second, a dermatologist is able to detect even discrete lesions. Last, although memory bias is undeniable in recording acute dermatitis, its effect is reduced when a dermatologist who is aware of the different forms of radiodermatitis performs a detailed history record. In any case, if such a recall bias existed, it did not impact the evaluation of late-onset radiodermatitis frequency. 
In conclusion, this study identified a late-onset radiodermatitis after FGI procedures in $8.8 \%$ of cases, which is the highest rate reported to date mainly because patients were systematically examined by a skin specialist. Irradiation parameters (air Kerma level, DAP value) and patients' BMI were the only risk factors identified. Several questions remain unanswered, including other risk factors due to patient characteristics, the long-term outcome of sclerotic lesions, their treatment and the risk of skin cancer.

\section{REFERENCES:}

1. Lichtenstein DA, Klapholz L, Vardy DA, Leichter I, Mosseri M, Klaus SN, et al. Chronic radiodermatitis following cardiac catheterization. Arch Dermatol. 1996; 132:663-7.

2. D'Incan M, Roger H. Radiodermatitis following cardiac catheterization. Arch Dermatol. 1997; $133: 242-3$.

3. Haute Autorité de Santé. Améliorer le suivi des patients en radiologie interventionnelle et actes radioguidés Réduire le risque d'effets déterministes. 2014. Available from: https://www.hassante.fr/portail/upload/docs/application/pdf/2014-07/radiologie_interventionnelle_v10_2014-0708_16-46-50_792.pdf

4. Vlietstra RE, Wagner LK, Koenig T, Mettler F. Radiation burns as a severe complication of fluoroscopically guided cardiological interventions. J Intervent Cardiol. 2004; 17:131-42.

5. Wei K-C, Yang K-C, Mar G-Y, Chen L-W, Wu C-S, Lai C-C, et al. STROBE-Radiation Ulcer: An Overlooked Complication of Fluoroscopic Intervention. Medicine. 2015; 94: 1-6.

6. Kirkwood ML, Arbique GM, Guild JB, Timaran C, Valentine RJ, Anderson JA. Radiationinduced skin injury after complex endovascular procedures. J Vasc Surg. 2014; 60:742-8.

7. Kato M, Chida K, Sato T, Oosaka H, Tosa T, Munehisa M, et al. The necessity of follow-up for radiation skin injuries in patients after percutaneous coronary interventions: radiation skin injuries will often be overlooked clinically. Acta Radiol Stockh Swed 1987. 2012; 53:1040-4.

8. NCRP 2014. Outline of Administrative Policies for Quality Assurance and Peer Review of Tissue Reactions Associated with Fluoroscopically-Guided Interventions. 2014; Available from: http://ncrponline.org/wp-content/themes/ncrp/PDFs/Statement_11.pdf 

Patient Skin Dose Evaluated Using Radiochromic Film and Dose Calculation Software. Cardiovasc

254

255

256

257

258 Intervent Radiol. 2018;41:762-71.

10. Yanch JC, Behrman RH, Hendricks MJ, McCall JH. Increased radiation dose to overweight and obese patients from radiographic examinations. Radiology. 2009; 252:128-39.

11. Jaschke W, Schmuth M, Trianni A, Bartal G. Radiation-Induced Skin Injuries to Patients: What the Interventional Radiologist Needs to Know. Cardiovasc Intervent Radiol. 2017; 40:1131-40.

12. Koenig TR, Wolff D, Mettler FA, Wagner LK. Skin injuries from fluoroscopically guided procedures: part 1, characteristics of radiation injury. AJR Am J Roentgenol. 2001; 177:3-11.

13. Chida K, Kato M, Kagaya Y, Zuguchi M, Saito H, Ishibashi T, et al. Radiation dose and radiation protection for patients and physicians during interventional procedure. J Radiat Res. 2010; 51:97-105.

14. Rigotti G, Marchi A, Galiè M, Baroni G, Benati D, Krampera M, et al. Clinical treatment of radiotherapy tissue damage by lipoaspirate transplant: a healing process mediated by adipose-derived adult stem cells. Plast Reconstr Surg. 2007; 119:1409-1422; discussion 1423-1424.

15. Mohan A, Singh S. Use of fat transfer to treat a chronic, non-healing, post-radiation ulcer: a case study. J Wound Care. 2017; 26:272-3.

16. Hymes SR, Strom EA, Fife C. Radiation dermatitis: Clinical presentation, pathophysiology, and treatment 2006. J Am Acad Dermatol. 2006; 54:28-46.

17. Balter S, Hopewell JW, Miller DL, Wagner LK, Zelefsky MJ. Fluoroscopically guided interventional procedures: a review of radiation effects on patients' skin and hair. Radiology. 2010; 254:326-41.

\section{Legends}


279 Table 1: Patients' characteristics.

\section{Phototypes:}

282 1: Hair: Red/blonde. Eyes: blue, grey, green. Skin: Very pale white, pale white. Tanning ability:

283 burns very easily, never tans.

2: Hair: Red/blonde/light brown. Eyes: Blue, grey, green, hazel. Skin: Pale white. Tanning ability: burns easily, rarely tans.

3: Hair: Chestnut, dark blonde. Eyes: Brown, blue, grey, green, hazel. Skin: White, light brown.

Tanning ability: Sometimes burns, gradually tans.

4: Hair: Brown, medium brown, dark brown. Eyes: Hazel, brown. Skin: Medium brown, dark brown.

Tanning ability: Hardly ever burns, tans very easily. darkens.

6: Hair: Black. Eyes: Brown. Skin: Black. Tanning ability: Never burns, tans very dark.

Table 2: Patients with chronic radiodermatitis.

304 Figure: Clinical aspects of cutaneous lesions 

chemoembolization. (Patient 4 table 2) Table 2)

312 malformation embolization. (Patient 7 Table 2) 


\section{APPENDIX 1: Statistical analyses}

Risk factors for radiodermatitis onset were assessed in populations with radiodermatitis and those without by the chi2 test in univariate analysis and the log rank test in multivariate analysis. Patient characteristics and radiation exposure data were compared in patients with radiodermatitis and those without. Analyses were performed with Stata software (Version 13, StataCorp, College Station, TX) for a two-sided Type I error at 5\%. Patient characteristics were expressed as mean \pm standard deviation (SD) or median [interquartile range] for continuous data (assumption of normality assessed by the Shapiro-Wilk test) and as numbers and associated percentages for categorical parameters. When appropriate, the results were expressed with a 95\% confidence interval. The continuous variables were compared in two groups of patients (with and without radiodermatitis) by Student's t-test or the MannWhitney test if the assumptions of the t-test were not met ([i] normality and [ii] homoscedasticity as assessed by the Fisher-Snedecor test). Categorical data comparisons were performed by the chi-squared or Fischer's exact tests. For repeated data, analyses were carried out with random-effect models to take into account inter- and intra-patient variability (patient as random effect). Multivariable analyses were performed with adjustment for DAP. Results were expressed as odds-ratio (OR) and 95\% confidence interval. 


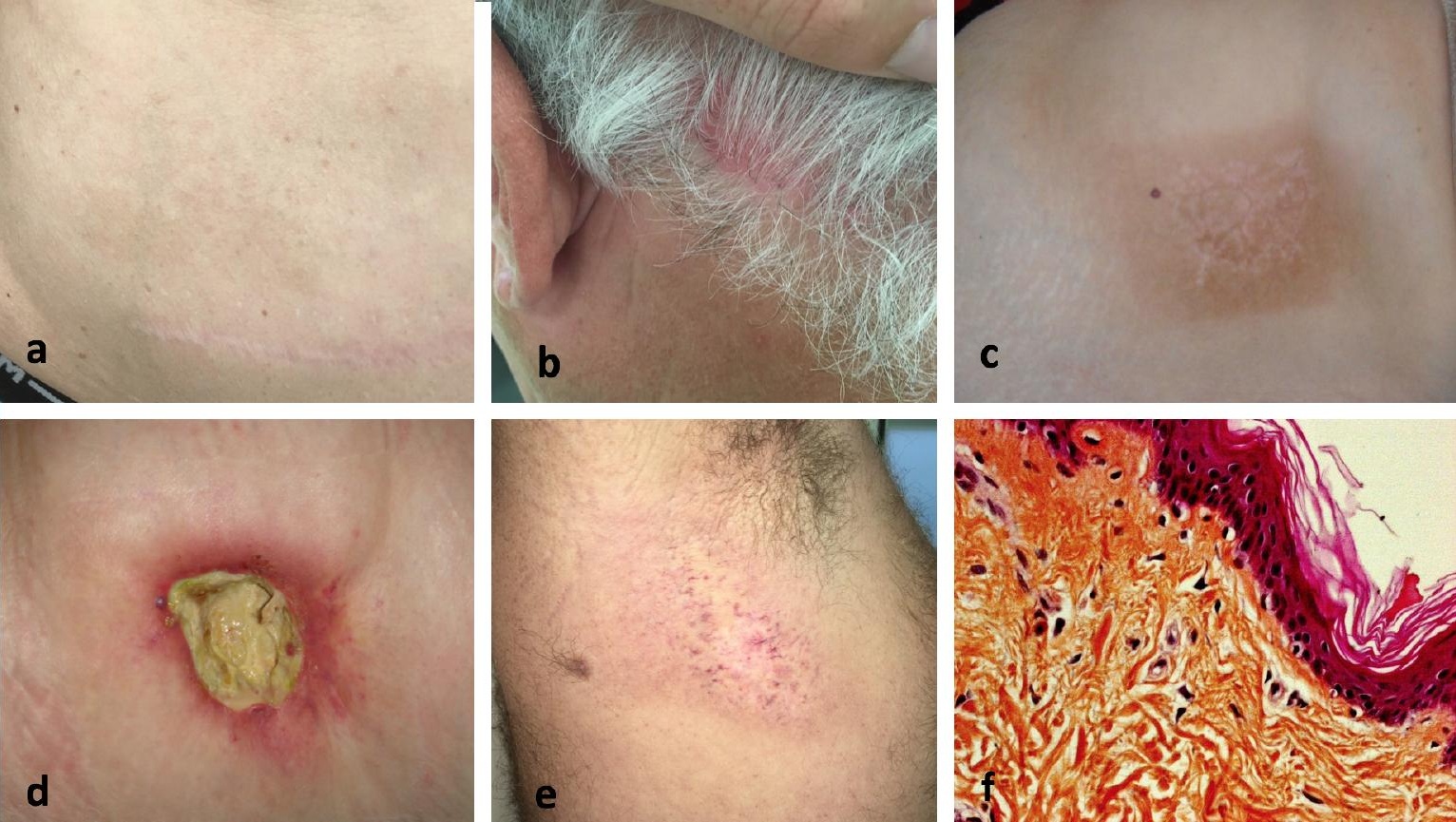




\title{
Table 1. Patient's characteristics
}

\section{Gender}

Age (years), median [IQR]

BMI $\left(\mathrm{kg} / \mathrm{m}^{2}\right)$, median [IQR]

\section{Phototype}

Diabetes

Previous exposition in the same skin area

\section{Procedure type}

1. Endovascular cephalic interventional neuroradiology

2. Cardiac procedure (PTCA, interventional rythmology)

3. Vascular peripheral interventional radiology (supra-aortic trunks, thoraco-abdomino-pelvic and limbs vessels)

\author{
Renal artery \\ Chemoembolization \\ Aorta (EVAR and other procedures) \\ Mesenteric artery \\ Splenic artery \\ Pulmonary embolization \\ Post-partum hemorrhage \\ Digestive embolization \\ Hepatic artery \\ Iliac angioplasty \\ Hypogastric embolization \\ Duodenopancreatic aneurism \\ Pelvic embolization \\ Portal embolization \\ TIPS \\ Epistaxis \\ Gluteal artery revascularization \\ Carotid \\ Muscular hematoma embolization
}

Fluoroscopy Time ( $\mathrm{min}$ ), median [IQR]

Air Kerma (Gy), median [IQR] 
Table 2. Eight patients with chronic radiodermatitis.

PATIENT

PROCEDURE

SEMIOLOGY

\begin{tabular}{|c|c|c|c|c|c|c|c|c|c|c|c|c|c|}
\hline $\mathbf{N}^{\circ}$ & Sex & Age & BMI & Phototype & Medical history & Type & $\begin{array}{l}\text { F. time } \\
(\min )\end{array}$ & $\begin{array}{c}\text { DAP } \\
\left(G y . \mathrm{cm}^{2}\right)\end{array}$ & $\begin{array}{l}\text { AK } \\
\text { (Gy) }\end{array}$ & $\begin{array}{c}\text { Acute } \\
\text { RD }\end{array}$ & localization & semiology & time to onset \\
\hline 1 & $\mathrm{~F}$ & 44 & 37.8 & 3 & & $\begin{array}{l}\text { uterine arteries } \\
\text { embolization (postpartum } \\
\text { hemorrhage) }\end{array}$ & 31 & 2530 & 4.65 & & lumbar & Large sclerotic area & 3 months \\
\hline 2 & $\mathrm{~F}$ & 81 & 30.8 & 3 & $\begin{array}{c}\text { Diabetes, } \\
\text { Photosensitizing } \\
\text { treatment }\end{array}$ & $\begin{array}{l}\text { Mesenteric artery } \\
\text { angioplasty }\end{array}$ & 61 & 2095 & 11 & & left flank & $\begin{array}{l}\text { Ulcer with sclerotic } \\
\text { banks }\end{array}$ & 5 months \\
\hline 3 & M & 80 & 27.8 & 4 & & $\begin{array}{l}\text { hypogastric artery } \\
\text { embolization + aortic } \\
\text { aneurysm prosthesis }\end{array}$ & 36 & 974 & 2.69 & & lumbar & $\begin{array}{l}\text { Hypopigmented } \\
\text { patch }\end{array}$ & Unknown \\
\hline \multirow[t]{2}{*}{4} & M & 67 & 31.4 & 3 & & $\begin{array}{l}\text { hepato carcinoma } \\
\text { chemoembolization } 1\end{array}$ & 8 & 319 & 0.68 & & & & \\
\hline & & & & & Previous procedure & $\begin{array}{l}\text { hepato carcinoma } \\
\text { chemoembolization } 2\end{array}$ & 13 & 740 & 2.39 & & upper right quadrant & $\begin{array}{l}\text { Hyperpigmented } \\
\text { lesion }\end{array}$ & Unknown \\
\hline 5 & M & 49 & 31.7 & 4 & $\begin{array}{l}\text { Photosensitizing } \\
\text { treatment }\end{array}$ & interventional cardiology & 40 & 1427 & 4.29 & & $\begin{array}{l}\text { right sub } \\
\text {-scapularis }\end{array}$ & $\begin{array}{l}\text { Hypopigmented } \\
\text { patch }\end{array}$ & Unknown \\
\hline 6 & M & 70 & 32.8 & 4 & & $\begin{array}{l}\text { neuro-radiology : cerebral } \\
\text { aneurysm embolization }\end{array}$ & 73 & 386 & 3.94 & & occipital & $\begin{array}{l}\text { Erythematous } \\
\text { plaque }\end{array}$ & Unknown \\
\hline 7 & M & 45 & 39.2 & 3 & $\begin{array}{c}\text { Photosensitizing } \\
\text { treatment } \\
\text { Previous procedure } \\
\text { for embolization } 2\end{array}$ & $\begin{array}{l}\text { pulmonary arteriovenous } \\
\text { malformation } \\
\text { embolization } 1 \\
\text { embolization } 2\end{array}$ & 59 & 1487 & 10.24 & $x$ & right axillary fold & $\begin{array}{l}\text { Atrophic plaque, } \\
\text { numerous } \\
\text { telangiectases }\end{array}$ & $\begin{array}{l}2 \text { weeks (after } \\
\text { embolization } 1 \text { ) }\end{array}$ \\
\hline
\end{tabular}


\begin{tabular}{llllll}
\hline 8 & $M$ & 71 & 38.3 & 4 & Diabetes,
\end{tabular}

Diabetes,
Photosensitizin

treatment
Abdominal muscular

bleeding embolization 